\title{
Health through awareness
}

\section{Perspective}

How many times have you heard people say: "I didn't know that!"? We hear it all the time. For instance, when we explain to people that every vegetable has protein, they usually say "I didn't know that!". Cooking, meal/menu planning, nutrition and other information used to be provided to children in 'Home Ec' class. While it, historically, was presented to young girls, many schools had a broader focus to include young boys. Children who graduated High School had a basic understanding how to care for themselves, cook a basic meal, do laundry and balance a check book. Today, many/most of these skills are not taught and kids today wander around in a digital haze, not understanding the basic skills of living and how to exist and care for themselves. Most kids have no idea how to do their own laundry or prepare a simple but nutritious meal. Fast food has taken over the world with easy, but poor nutrition stuff that too many eat; thinking it is actually FOOD. These undereducated children have now grown to adults and most, still can't cook a decent meal. They rely on fast food, pizza, burgers and other stuff that contains high fat, high salt and sugar and very little balanced nutrition. When you ask them about eating green/colored vegetables they usually roll their eyes or say 'yuck' and ignore the rest of any information you may try to offer. Balanced meals, Real Nutrition, presented in a delicious, appetizing way are mostly never seen in today's households. Americans (and others) eat a very limited variety of 'food' that they subsist upon. If they do prepare a meal at home, it is usually the same bland piece of chicken and, if lucky, maybe some green beans and potatoes. The meal is more of a necessity than delicious cuisine, easily prepared, to enjoy and nourish your body. Variety is missing and variety is not only the spice of life but should be the Spice in your Food. The delicious natural goodness of real Whole Food, not processed, boxed over salted, fat saturated junk that most Americans subsist on is seldom found on most American Dinner Tables. Even restaurants must continue the lousy food choices, simply because that is what most Americans have gotten used to eating and what sells. True Cuisine is usually missing replaced by repeating the high fat, high salt and sugary 'food' that Americans are accustomed to eating. If people actually try to eat vegetables (even in restaurants), they are usually overcooked and mushy and unseasoned so taste horrid if there is any taste left at all (Figure 1).

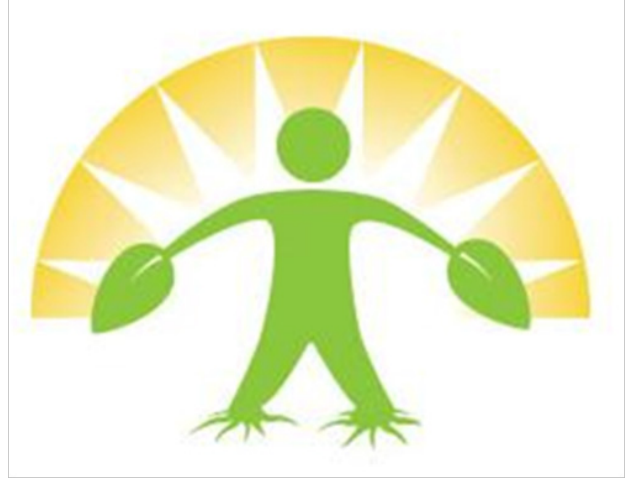

Figure I Health through awareness.
Volume 6 Issue 2 - 2017

Skip Stein
Plant Based Lifestyle Consultant, Whole Foods 4 Healthy Living,
USA

Correspondence: Skip Stein, Plant Based Lifestyle Consultant, Chief Operating Officer,Whole Foods 4 Healthy Living, Orlando, USA, Tel 40768368I6, Email SkipStein@newtimers.org

Received: January 20, 2017 | Published: March 22, 2017

\section{Medical industry}

The medical and pharmaceutical industry gets immense benefits and profits from the lousy diet/nutrition of Americans. Because most Americans just don't know any better, they continue to exist eating junk food that results in a plethora of diseases; some more serious than others. Poor nutrition results in a compromised immune system. This in turn results in the body's inability to fight off common disease and infections that most people are exposed to every day. People get the flu, colds and worse. A compromised immune system can allow the growth of cancer, build up of plaque in arteries and the imbalance of your glycemic levels that will lead to diabetes. To see just how bad this condition is, all one has to do is watch a bit of broadcast television. So, may commercials for pharmaceutical products to treat lifestyle disease, many of which have their root cause in a compromised immune system. Poor quality food compromises the immune system and a compromised immune system leads to disease. The Medical Industry today focuses on treatment of disease but never seems to be concerned with the Cause of disease. Since the cause of many to most of today's common diseased (heart disease, cancer, diabetes) infect those with a compromised immune system, it would seem like more attention should be paid to prevention and strengthening the immune system and less reliance on treatment.

\section{Awareness}

America has one of the biggest and most complex medical/ pharmaceutical industries on the Planet but, yet, we are some of the sickest people on the Planet! Why is that? Could it be because Americans, for the majority, subsist on junk food, poor nutrition and are simply Not Aware of what they are consuming? We think this to be the case! Instead of spending billion\$ more on treatment centres for heart disease, cancers and diabetes, wouldn't it be better and more cost effective to simply make more people AWARE of the nature of their FOOD, what they eat and how it is damaging their ability to be Healthy? Shouldn't the focus be on Prevention, not Treatment? Prevention is Cheap. Eating healthier food is a low-cost alternative to the horrendous costs of prescription drugs, surgeries and constant treatment for diseases that should have been PREVENTED in the first 
place! Awareness and education programs are cheaper than medical school and the results could be amazing. Reducing the pervasive diseases that face Americans would allow more focus on those rare, less common diseases that still plague Americans. Eliminate the easy fixes and focus on the real problems! Awareness is key. Only the suicidal will want to persist in behavior that they have been made aware is dangerous and potentially deadly. Disease is Expensive but Health is actually cheaper. Prevention truly IS worth a pound of treatment with drugs \& surgery.

\section{Prevention is Cheap when compared with the Cost of} Treatment!

\section{Acknowledgements}

None.

\section{Conflict of interest}

Author declares that there is no conflict of interest. 